\title{
Somatosensory Temporal Discrimination Threshold in Patients with Cognitive Disorders
}

\author{
Fabrizia D’Antonio ${ }^{\mathrm{a}, \mathrm{b}, *}$, Maria Ilenia De Bartolo ${ }^{\mathrm{a}}$, Gina Ferrazzano ${ }^{\mathrm{c}}$, Alessandro Trebbastoni $^{\mathrm{a}}$, \\ Sara Amicarelli ${ }^{\mathrm{a}}$, Alessandra Campanelli ${ }^{\mathrm{a}}$, Carlo de Lena ${ }^{\mathrm{a}}$, Alfredo Berardelli ${ }^{\mathrm{a}, \mathrm{c}}$ \\ and Antonella Conte ${ }^{\mathrm{a}, \mathrm{c}}$ \\ ${ }^{a}$ Department of Human Neuroscience, Sapienza University of Rome, Rome Italy \\ ${ }^{\mathrm{b}}$ PhD Program in Behavioral Neuroscience, Sapienza University of Rome, Rome, Italy \\ ${ }^{\mathrm{c}}$ IRCCS Neuromed, Pozzilli (IS), Italy
}

Accepted 6 May 2019

\begin{abstract}
.
Background: The temporal processing of sensory information can be evaluated by testing the somatosensory temporal discrimination threshold (STDT), which is defined as the shortest interstimulus interval needed to recognize two sequential sensory stimuli as separate in time. The STDT requires the functional integrity of the basal ganglia and of the somatosensory cortex (S1). Although there is evidence that time processing is impaired in patients with Alzheimer's disease (AD), no study has yet investigated STDT in patients with various degree of cognitive impairment.

Objective: The aim of our study was to understand how cognition and attention deficits affect STDT values in patients with cognitive abnormalities.

Methods: We enrolled 63 patients: 28 had mild-moderate AD, 16 had mild cognitive impairment (MCI), and the remaining 19 had subjective cognitive deficit (SCD). A group of 45 age-matched healthy subjects acted as controls. Paired tactile stimuli for STDT testing consisted of square-wave electrical pulses delivered with a constant current stimulator through surface electrodes over the distal phalanx of the index finger.

Results: STDT values were higher in AD and MCI patients than in SCD subjects or healthy controls. Changes in the STDT in AD and MCI were similar in both conditions and did not correlate with disease severity.

Conclusions: STDT alterations in AD and MCI may reflect a dysfunction of the dopaminergic system, which signals salient events and includes the striatum and the mesocortical and mesolimbic circuits.
\end{abstract}

Keywords: Alzheimer's disease, mild cognitive impairment, somatosensory temporal discrimination threshold, subjective cognitive decline, temporal processing

\section{INTRODUCTION}

Temporal processing and time perception can be investigated by means of several methods whose level

\footnotetext{
*Correspondence to: Fabrizia D'Antonio, Department of Human Neuroscience, Sapienza University of Rome, Viale dell'Università 30, 00185, Rome, Italy. Tel.: +39 0649914129; E-mail: fabrizia.dantonio@uniroma1.it.
}

of complexity ranges from basic levels, which include temporal discrimination, perception of simultaneity of two stimuli and discrimination of temporal order, to more complex levels, which include perception of duration and perception of time flow [1-3]. Time perception has been investigated in Alzheimer's disease (AD) with neuropsychological paradigms consisting of verbal time estimation, verbal time production or reproduction, and interval comparison in order to evaluate time interval length [4-10]. These studies 
showed that $\mathrm{AD}$ patients had an impairment in time processing and they had significant alterations in the judgment of time duration [11]. Only few studies have investigated time perception in mild cognitive impairment (MCI) and they reported normal findings [6, 12]. Conversely, there is evidence that the subjective experience of time is altered even at the early stage of cognitive impairment (MCI) [12].

Temporal processing can be also evaluated by using a simple method that assesses the ability to recognize two sequential sensory stimuli as separate in time (somatosensory temporal discrimination threshold - STDT). STDT has never been tested in patients with AD and MCI. STDT testing requires the functional integrity of both the basal ganglia-within a network that integrates and selects incoming sensory information through the dopamine-mediated alerting system $[13,14]$ —and the somatosensory cortex (S1) $[15,16]$.

In particular, the $\mathrm{S} 1$ sharpens sensory information through inhibitory cortical interneuron activity [15]. The STDT is also partly regulated by the presupplementary motor area (SMA), anterior cingulate cortex, and associative parietal cortex, as demonstrated by functional magnetic resonance imaging (fMRI) studies [17]. As STDT testing involves attention-demanding procedures [15, 17], understanding how cognition and attention deficits affect STDT values has relevant implications for studies that include STDT testing in patients with neurological conditions. In the present study we investigated the STDT in patients with cognitive impairment by enrolling patients with $\mathrm{AD}, \mathrm{MCI}$, and subjective cognitive decline (SCD). SCD is a condition characterized by a self-perceived cognitive impairment that is not detected by neuropsychological tests and is considered a preclinical stage of dementia $[18,19]$. To see whether possible changes of STDT values in patients with cognitive disorders are due to agingrelated effects, the results from $\mathrm{AD}, \mathrm{MCI}$, and SCD patients were compared with those from a group of age-matched healthy subjects.

\section{MATERIALS AND METHODS}

\section{Subjects}

We enrolled 63 subjects from the Alzheimer's Unit at the Department of Human Neurosciences, Sapienza University of Rome: 28 had mild-moderate AD, 16 had MCI, and the remaining 19 had SCD. Forty-five age-matched healthy volunteers with no evidence of cognitive impairment were consecutively enrolled from among the unaffected partners of patients attending the Department of Human Neurosciences, Sapienza University of Rome, Italy. The diagnosis of probable AD and MCI was made according to the clinical criteria from the National Institute on Aging-Alzheimer's Association workgroups (NIA-AA) [20, 21]. The diagnosis of SCD was based on subjective cognitive decline criteria [22]. The patients' demographic and clinical characteristics are shown in Table 1.

The patients underwent a physical and neurological assessment, standard laboratory tests, serum vitamin B12, folate, and thyroid hormone assays as well as a neuropsychological evaluation. AD patients were included if they were between 55 and 85 years of age, had an Mini-Mental State Examination (MMSE) score between 15 and 26, a Clinical Dementia Rating (CDR) score between 0.5 and 2, and a Modified Hachinski Ischemic Score of 4. MCI patients were included if they were between 55 and 85 years of age, had an MMSE score between 20 and 26, and a CDR score equal to 0 . SCD subjects were included if they were between 55 and 85 years of age, had an MMSE score higher than 27 and a CDR score equal to 0 , and had undergone an MRI scan that revealed cortical atrophy involving the medial temporal lobes [23]. Patients were excluded if they had secondary causes of dementia, degenerative dementia other than $\mathrm{AD}$, or vascular dementia diagnosed according to the National Institute of Neurological Disorders and Stroke and Association Internationale pour la Recherche et l'Enseignement en Neurosciences (NINDS-AIREN) criteria [24]. Patients and healthy subjects were excluded if they had psychiatric comorbidities, if they had had repeated head trauma, protracted loss of consciousness following head trauma or severe central nervous system infections within the last 5 years, or if they had a history of cerebrovascular disease (i.e., stroke, transient ischemic attacks, cerebral hemorrhage). Subjects who had a clinically-diagnosed peripheral sensory neuropathy or who presented major risk factors for neuropathy (e.g., diabetes, chronic metabolic diseases, autoimmune diseases) were not included in the study either. Patients who were taking antipsychotic drugs were excluded while those taking anticholinesterase inhibitors were not. The study was conducted in accordance with the Declaration of Helsinki and was approved by the Local Ethics Committee. All the participants, or their caregivers, gave their written informed consent. 
Table 1

Demographics and clinical characteristics of SCD, MCI, and AD patients

\begin{tabular}{|c|c|c|c|c|c|}
\hline & $\operatorname{SCD}(n=19)$ & $\operatorname{MCI}(n=16)$ & $\mathrm{AD}(n=28)$ & Test & $p$ \\
\hline $\operatorname{Age}(y$, mean $\pm S D)$ & $68.4( \pm 6)$ & $71.6( \pm 9.5)$ & $78( \pm 4.7)$ & $\mathrm{H}=21.3$ & $<0.01$ \\
\hline Gender (Male, number and \%) & $4(21 \%)$ & $9(56.2 \%)$ & $15(53.6 \%)$ & $\chi^{2}=6$ & $<0.05$ \\
\hline Education $(y$, mean $\pm \mathrm{SD})$ & $12.5( \pm 3.1)$ & $9.9( \pm 4.8)$ & $9.04( \pm 4.2)$ & $\mathrm{H}=8.6$ & $<0.05$ \\
\hline $\operatorname{MMSE}($ mean \pm SD) & $28.1( \pm 1.8)$ & $22.5( \pm 2.9)$ & $20,1( \pm 2.7)$ & $\mathrm{H}=39.4$ & $<0.01$ \\
\hline RAVLT immediate recall (mean $\pm \mathrm{SD}$ ) & $43.3( \pm 9.9)$ & $34.8( \pm 8)$ & $27,3( \pm 6.5)$ & $\mathrm{H}=22.9$ & $<0.01$ \\
\hline RAVLT delayed recall $($ mean $\pm S D)$ & $9.2( \pm 2.5)$ & $5.8( \pm 4.7)$ & $1,4( \pm 2.5)$ & $\mathrm{H}=31.6$ & $<0.01$ \\
\hline Babcock immediate recall $($ mean $\pm S D)$ & $5.4( \pm 1.3)$ & $3.7( \pm 2.5)$ & $1,7( \pm 1.9)$ & $\mathrm{H}=22.8$ & $<0.01$ \\
\hline Babcock delayed recall $($ mean $\pm S D)$ & $6.2( \pm 1.6)$ & $3.8( \pm 2.8)$ & $1,5( \pm 2.4)$ & $\mathrm{H}=26.5$ & $<0.01$ \\
\hline $\mathrm{DS}($ mean $\pm \mathrm{SD})$ & $5.5( \pm 0.8)$ & $5( \pm 0.8)$ & $5( \pm 0.6)$ & $\mathrm{H}=6.4$ & $<0.05$ \\
\hline $\mathrm{CT}($ mean $\pm \mathrm{SD})$ & $4.7( \pm 0.8)$ & $3.8( \pm 0.7)$ & $3,9( \pm 0.7)$ & $\mathrm{H}=10.5$ & $<0.05$ \\
\hline ROCF immediate recall $($ mean $\pm S D)$ & $18.1( \pm 8.1)$ & $6.2( \pm 4.9)$ & $4,4( \pm 4.2)$ & $\mathrm{H}=30.4$ & $<0.01$ \\
\hline ROCF delayed recall $($ mean $\pm S D)$ & $18.6( \pm 7.8)$ & $4.5( \pm 4.6)$ & $4,6( \pm 4.5)$ & $\mathrm{H}=34$ & $<0.01$ \\
\hline $\mathrm{VS}($ mean $\pm \mathrm{SD})$ & $52( \pm 4)$ & $43.9( \pm 6.9)$ & $42( \pm 9.6)$ & $\mathrm{H}=17.3$ & $<0.01$ \\
\hline TMT-A $($ mean \pm SD) & $54.4( \pm 18.7)$ & $98.1( \pm 33.1)$ & $113( \pm 46.2)$ & $H=23.6$ & $<0.01$ \\
\hline TMT-B $($ mean \pm SD) & $74.7( \pm 42.8)$ & $245.3( \pm 87.6)$ & $257( \pm 79.5)$ & $\mathrm{H}=34.4$ & $<0.01$ \\
\hline $\mathrm{VPF}($ mean $\pm \mathrm{SD})$ & $36.3( \pm 8.4)$ & $23.6( \pm 6)$ & $22,7( \pm 6.4)$ & $\mathrm{H}=24.2$ & $<0.01$ \\
\hline $\mathrm{VSF}($ mean $\pm \mathrm{SD})$ & $43.7( \pm 9.2)$ & $30.3( \pm 6.5)$ & $26,7( \pm 6.8)$ & $\mathrm{H}=31.9$ & $<0.01$ \\
\hline $\mathrm{BNT}($ mean $\pm \mathrm{SD})$ & $29.2( \pm 2.5)$ & $30.2( \pm 9.5)$ & $27( \pm 6.9)$ & $\mathrm{H}=10.3$ & $<0.01$ \\
\hline $\mathrm{CDT}($ mean $\pm \mathrm{SD})$ & $1.5( \pm 0.7)$ & $2.5( \pm 1.4)$ & $3,3( \pm 1.1)$ & $\mathrm{H}=19.4$ & $<0.01$ \\
\hline ROCF copy (mean \pm SD) & $33( \pm 3.3)$ & $24.5( \pm 11.4)$ & $20,5( \pm 6.2)$ & $\mathrm{H}=9.9$ & $<0.01$ \\
\hline $\mathrm{FAB}($ mean $\pm \mathrm{SD})$ & $17.4( \pm 1.4)$ & $14.6( \pm 2.4)$ & $13,5( \pm 2.7)$ & $\mathrm{H}=24$ & $<0.01$ \\
\hline $\mathrm{RCPM}($ mean $\pm \mathrm{SD})$ & $28.8( \pm 5)$ & $25.2( \pm 5.7)$ & $20,5( \pm 6.2)$ & $H=16.5$ & $<0.01$ \\
\hline
\end{tabular}

SCD, subjective cognitive decline; MCI, mild cognitive impairment; AD, Alzheimer's disease; MMSE, Mini-Mental State Examination; RAVLT, Rey's auditory verbal learning test; DS, Digit span; CT, Corsi block-tapping test; ROCF, Rey-Osterrieth complex figure test; VS, Visual-Search Matrix-test; TMT-A, Trail-Making test part A; TMT-B, Trail-Making test part B; VPF, Phonemic Verbal Fluency test; VSF, Semantic Verbal Fluency test; BNT, Boston Naming test; CDT, Clock Drawing test; FAB, Frontal Assessment Battery; RCPM, Raven's Progressive Colored Matrices.

\section{Neuropsychological evaluation}

All the patients underwent a complete neuropsychological evaluation including the MMSE [25], as a measure of global cognitive decline, activities of daily living (ADL) and instrumental activities of daily living (IADL) to assess functional impairment [26]. Patients also underwent: Rey's auditory verbal learning test (RAVLT), Babcock story recall test [27], the Corsi block-tapping test (CT) [28] and Digit span (DS) [29] to assess memory; the Visual-Search Matrix-test (VS) [29] and the Trail-Making test part A (TMT-A) and part B (TMT-B) [30] to assess attentional function; the Boston Naming test (BNT) [31], the Semantic Verbal Fluency test (VSF) and the Phonemic Verbal Fluency test (VPF) [32] to assess verbal functions; the Clock Drawing test (CDT) [33] and Rey-Osterrieth complex figure test (ROCF) [27] to assess visuoperceptual functions; the Frontal Assessment Battery (FAB) [34] and Raven's Progressive Coloured Matrices (RCPM) [35,36] to assess frontal functions. Healthy subjects underwent the Montreal Cognitive Assessment (MoCA) to assess global cognitive functions.

\section{STDT testing}

The STDT was investigated according to the experimental procedures used in previous studies [15, 37-41]. Paired tactile stimuli for STDT testing consisted of square-wave electrical pulses delivered by means of a constant current stimulator (Digitimer DS7AH) through surface electrodes over the distal phalanx of the right index finger. The stimulation intensity was defined for each subject by delivering a series of stimuli starting from an intensity of $2 \mathrm{~mA}$ that increased in $0.5 \mathrm{~mA}$ steps; the intensity used for STDT testing was the minimal intensity the subject perceived in 10 out of 10 consecutive stimuli. We delivered paired stimuli by starting with an interstimulus interval (ISI) of $0 \mathrm{~ms}$ (simultaneous pair) and progressively increasing the ISI in $10 \mathrm{~ms}$ steps. The first of three consecutive ISIs at which participants recognized the stimuli as temporally separate was considered the STDT. The STDT was defined as the average of three STDT trials and entered in the data analysis. To ensure that the subjects' attention levels remained high throughout STDT testing, we delivered random single stimulus "catch trials". 
If subjects were not consistent in the catch trials, the STDT value obtained was discarded from the analysis and the STDT was retested.

\section{Statistical analysis}

The statistical analysis was performed using SPSS (vers. 24). We compared the demographic and clinical characteristics of the AD and MCI patients and SCD subjects by performing a Kruskall-Wallis test and Mann-Whitney $U$ test for the post-hoc analysis. We performed an ANOVA including age and education as covariate to detect possible differences in STDT values between the three samples of patients and healthy subjects. We also performed ROC curve analyses to identify the cut-off STDT value that yielded the highest discriminative ability for differentiating patients with cognitive impairment (MCI and AD) from healthy subjects. Moreover, Spearman's Rho Correlation Coefficient between STDT values and neuropsychological scores obtained in MCI, AD, and SCD subjects was calculated. Lastly, we ran a multiple regression analysis to detect any associations between STDT values and clinical variables that could be used to diagnose cognitive impairment. $p<0.05$ indicated statistical significance.

\section{RESULTS}

The patients' demographic and clinical characteristics and neuropsychological test scores are shown in Table 1 . In healthy subjects, MoCA mean score was $26.7 \pm 1.5$.

Three of the 63 patients responded inconsistently during the STDT testing and were thus excluded from the analysis.

AD patients were older than MCI patients and, as expected, they had a greater global cognitive functional impairment (measured by means of the MMSE, ADL, and IADL). AD patients also scored lower in all the tests that measured verbal memory and in the RCPM, which measures executive functions. AD and MCI patients did not significantly differ in education level. Subjects with SCD had a higher education level, were younger and performed better than $\mathrm{AD}$ patients in the neuropsychological tests $(p<0.001)$. Although SCD subjects were similar in age and had a similar education level to MCI patients, MCI patients performed worse than SCD in the neuropsychological tests $(p<0.001$; Table 1$)$.

When data from both the patients and healthy subjects were compared, the ANOVA yielded sig-

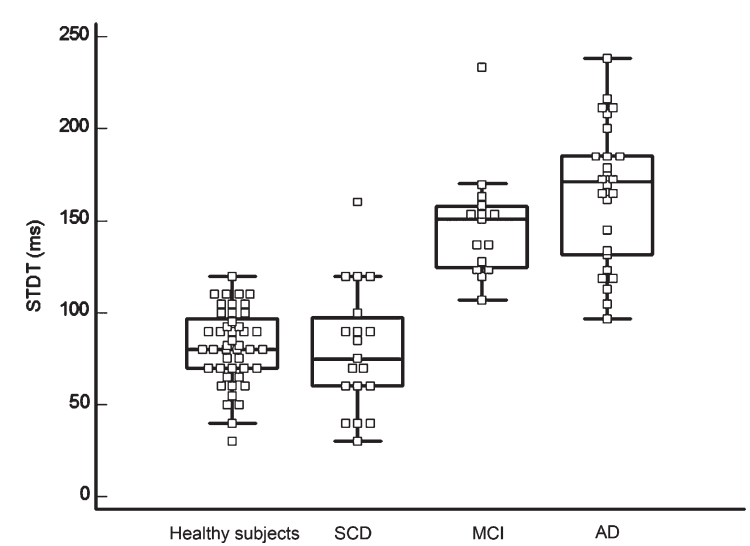

Fig. 1. Somatosensory temporal discrimination threshold (STDT) values in patients with cognitive disorders and healthy subjects. Open squares represent individual STDT values (from the left to the right) in Healthy subjects, Subjective cognitive decline (SCD), Mild cognitive impairment (MCI), and Alzheimer's disease patients (AD). Boxes represent mean STDT values \pm the standard deviation in each group.

nificantly different STDT values between AD and MCI patients, SCD subjects and healthy subjects $(F=66.2$ df: $3, p<0.0001)$ (Fig. 1). The post-hoc analysis showed that STDT values in patients with $\mathrm{AD}(p<0.001)$ and in patients with MCI $(p<0.001)$ were higher than those in healthy controls. STDT values in subjects with SCD were instead normal $(p=0.97)$. The post-hoc analysis also showed that the STDT did not significantly differ between MCI and $\mathrm{AD}(p=0.26)$. The ROC curve analysis, which was performed in order to identify cut-off values between patients with cognitive impairment and healthy subjects, showed that an STDT value equal to $110 \mathrm{~ms}$ yielded a $93.4 \%$ sensitivity and $98 \%$ specificity in discriminating patients with cognitive impairment (AD and MCI) from healthy subjects. STDT value higher than $120 \mathrm{~ms}$ corresponds to $100 \%$ positive predictive and STDT lower than $95 \mathrm{~ms}$ corresponds to $100 \%$ negative predictive value. Considering the " $110 \mathrm{~ms}$ STDT cut-off value", STDT was normal in only 2 of the patients with MCI and altered in only 4 subjects with SCD.

\section{Correlations between STDT values and neuropsychological scores}

No correlations emerged between the neuropsychological scores and STDT values in MCI and AD patients. The multiple regression analysis showed that STDT and MMSE values were significantly 
associated with a diagnosis of $\mathrm{MCI}$ and $\mathrm{AD}(p=0.03$ and $p=0.02$, respectively).

\section{DISCUSSION}

Our findings show that STDT values were higher in $\mathrm{AD}$ and MCI patients than in SCD subjects or healthy controls. STDT changes in AD and MCI were comparable in both conditions and did not correlate with disease severity.

The differences in STDT abnormalities we detected in $\mathrm{AD}$ and MCI patients might have been due to differences in age between the groups of subjects we studied. In healthy subjects, the STDT increases by $6.66 \mathrm{~ms}$ every ten years [42]. However, although MCI patients and SCD subjects were similar in age, STDT values were altered in MCI patients though not in SCD subjects. In addition, when STDT values in AD patients were compared with those in normal subjects of a similar age, the extent of the STDT increase was greater than might have been expected it been due to age-related mechanisms. We therefore rule out the possibility that aging-related effects were responsible for the STDT abnormalities we detected in AD and MCI. Education is another factor that might affect the STDT. However, although the level of education was lower in AD patients than in SCD subjects, it was similar between MCI and SCD, and no differences emerged in the STDT values between AD and MCI. Hence, we also exclude the possibility that differences in education level may account for the increased STDT we observed in AD.

Moreover, in order to rule out the possibility that any STDT changes might be due to a misinterpretation of the task due to severe cognitive impairment, we included only patients who gave stable and reproducible responses across the STDT trials, excluding those who gave very inconsistent responses, as evaluated by means of the catch trials.

The STDT involves cortical and subcortical processing. Previous investigations based on noninvasive brain stimulation $[15,16]$ and functional MRI [17, 43] have demonstrated that S1 and basal ganglia play a key role in the STDT. However, selective $\mathrm{S} 1$ involvement is unlikely to be responsible for STDT abnormalities in AD and MCI because the S1 is not involved in $\mathrm{AD}$, at least in the early phase of the neurodegenerative process [44]. Similarly, the increased STDT values are also unlikely to be due to selective basal ganglia damage because the patients we studied did not have parkinsonism or any clinical features that might be specific of basal ganglia disorders. STDT is also modulated by the pre-SMA, anterior cingulate cortex, and associative parietal cortex. Temporal processing involves the activation of cortico-striatal networks including ventral and dorsal striatum projecting to dorsolateral prefrontal cortex, SMA, and associative parietal cortices in which each region plays a different role in time perception [45]. Ventral and dorsal striatum may also intervene in attentional processes through their connections with frontal areas [46-50]. Indeed dopaminergic networks are involved in both interval timing and attention processes via mesocortical and mesolimbic networks [51-53]. Attentional deficits may interfere with all the stages of temporal processing varying from the early automatic encoding phase (STDT) to the more complex processes of the time perception. Consistently, we observed that the $\mathrm{AD}$ and MCI patients scored worse than SCD subjects in the TMT-A and TMT-B, which test attentional performance. Our hypothesis is that STDT alterations in $\mathrm{AD}$ and MCI reflect a dysfunction in the dopaminergic system, signaling salient events, that includes the dorsal and ventral striatum (parts of the mesocortical and mesolimbic circuits) and projects to the dorsolateral prefrontal cortex, somatosensory and associative parietal cortices $[54,55]$. Previous studies on mouse models of $\mathrm{AD}$ and $\mathrm{MCI}$ have revealed a loss of dopaminergic signaling in the ventral tegmental area (VTA) both before and after the onset of cognitive deficits [56]. De Marco et al. (2018) recently found a volume reduction in the VTA in patients with mild/moderate AD and $\mathrm{MCI}$ and suggested that VTA degeneration represents an early neuropathological marker of disease [57].

The observation that STDT changes in MCI and AD did not correlate with the neuropsychological evaluations suggests that STDT alterations and cognitive deficits are not linearly related. Our finding that STDT values and MMSE are independently associated with the diagnosis of $\mathrm{AD}$ and MCI suggests that both may be independent markers of disease status.

The fact that STDT values were normal in the majority of patients with subjective cognitive decline who did not have overt attentional deficits suggests that the STDT is altered only when attention is abnormal, as assessed by means of neurocognitive tests. The four patients with SCD (out of a total of 19 SCD patients) whose STDT values were abnormal according to the STDT cut-off values identified by the ROC curve analysis may have a preclinical condition. Longitudinal investigations on subjects with SCD may 
help to clarify whether subjects with increased STDT values in the SCD phase go on to develop MCI or AD.

One question that deserves attention is how the STDT may be interpreted within the context of mechanisms of time perception and processing. Time processing in normal subjects may be due to a centralized mechanism that encompasses different time scales or to independent circuits (local timing model) in different cortical areas [13]. However, regardless of whether the timing is based on a centralized or local timing model, an accepted model for time perception is the scalar timing theory, which is based on a three-phase process: clock, memory and decision phase [58, 59]. fMRI studies have demonstrated that the three phases of the model are underpinned by different brain regions and that the basal ganglia intervene in the encoding phase, acting as dopaminergic pacemaker $[45,60,61]$. Although the STDT is modulated by multiple cortical areas (i.e., pre-SMA, anterior cingulate cortex, and associative parietal cortex), STDT reflects a temporal processing that is more perceptual than cognitive and more automatic than conscious. It is therefore possible that dopaminergic mechanisms mediating the clock phase may be responsible for STDT abnormalities in AD and MCI.

In conclusion, based on previous neuropsychological studies on $\mathrm{AD}$ suggesting that the impairment in time perception may be due either to a slowing down of the internal clock mechanism or to reduced cognitive attentional resources and memory deficits $[4,6$, 8-10], STDT impairment likely reflects an automatic perceptive mechanism $[1,3,62]$ that may capture the clock phase of the scalar timing theory, which becomes abnormal when the subcortical (centralized) system is impaired. Cortico-striatal networks, including ventral and dorsal striatum, which are involved in both attentional mechanisms and time interval perception may play a key role in the alterations of STDT we found in $\mathrm{AD}$ and MCI patients.

This study has some limitations. The sample size was too small to draw any definitive conclusions from the STDT alterations regarding $\mathrm{MCI}$ and $\mathrm{AD}$. Moreover, since STDT values were similar in MCI and early $\mathrm{AD}$, we were unable to determine whether STDT alterations reflect disease severity. Longitudinal studies are needed to evaluate whether STDT values change over time and may be used as a marker of disease progression.

In conclusion, the results of our study show that the STDT is altered in AD and MCI patients but is normal in SCD subjects. This finding may be due to a dopaminergic dysfunction of the attention-related mesolimbic and mesocortical circuits. Further studies are needed to provide a better insight into the precise mechanisms underlying time perception and the neural areas underpinning the representation of time in the brain as well as into how they deteriorate in the various stages of cognitive impairment. The STDT should also be investigated in SCD subjects in a longitudinal study to determine whether STDT alterations may predict the conversion from SCD to MCI and AD.

\section{DISCLOSURE STATEMENT}

Authors' disclosures available online (https:// www.j-alz.com/manuscript-disclosures/19-0385).

\section{REFERENCES}

[1] Artieda J, Pastor MA, Lacruz F, Obeso JA (1992) Temporal discrimination is abnormal in parkinson's disease. Brain 115, 199-210.

[2] Artieda J, Pastor MA (1996) Neurophysiological mechanisms of temporal perception. Adv Psychol 115, 1-25

[3] Lacruz F, Artieda J, Pastor MA (1991) The anatomical basis of somaesthetic temporal. J Neurol Neurosurg Psychiatry 54, 1077-1081.

[4] Carrasco MC, Guillem MJ, Redolat R (2000) Estimation of short temporal intervals in alzheimer's disease. Exp Aging Res 26, 139-151.

[5] Papagno C, Allegra A, Cardaci M (2004) Time estimation in Alzheimer's disease and the role of the central executive. Brain Cogn 54, 18-23.

[6] Rueda AD, Schmitter-Edgecombe M (2009) Time estimation abilities in mild cognitive impairment and Alzheimer's disease. Neuropsychology 23, 178-188.

[7] Caselli L, Iaboli L, Nichelli P (2009) Time estimation in mild Alzheimer's disease patients. Behav Brain Funct 5, $1-10$.

[8] El Haj M, Moroni C, Samson S, Fasotti L, Allain P (2013) Prospective and retrospective time perception are related to mental time travel: Evidence from Alzheimer's disease. Brain Cogn 83, 45-51.

[9] El Haj M, Omigie D, Moroni C (2014) Time reproduction during high and low attentional tasks in Alzheimer's Disease "A watched kettle never boils." Brain $\operatorname{Cogn}$ 88, 1-5.

[10] Nichelli P, Venneri A, Molinari M, Tavani F, Grafman J (1993) Precision and accuracy of subjective time estimation in different memory disorders. Cogn Brain Res 1, 87-93.

[11] El Haj M, Kapogiannis D (2016) Time distortions in Alzheimer's disease: A systematic review and theoretical integration. NPJ Aging Mech Dis 2, 1-5.

[12] Coelho S, Guerreiro M, Chester C, Silva D, Maroco J, Coelho M, Paglieri F, De Mendonça A (2016) Time perception in mild cognitive impairment: Interval length and subjective passage of time. J Int Neuropsychol Soc 22, 755764.

[13] Ivry RB, Spencer RMC (2004) The neural representation of time. Curr Opin Neurobiol 14, 225-232. 
[14] Ivry RB (1996) The representation of temporal information in perception and motor control. Curr Opin Neurobiol 6, 851-857.

[15] Conte A, Rocchi L, Nardella A, Dispenza S, Scontrini A, Khan N, Berardelli A (2012) Theta-burst stimulationinduced plasticity over primary somatosensory cortex changes somatosensory temporal discrimination in healthy humans. PLoS One 7, 1-8.

[16] Rocchi L, Casula E, Tocco P, Berardelli A, Rothwell J (2016) Somatosensory temporal discrimination threshold involves inhibitory mechanisms in the primary somatosensory area. J Neurosci 36, 325-335.

[17] Pastor MA (2004) The functional neuroanatomy of temporal discrimination. J Neurosci 24, 2585-2591.

[18] Amariglio RE, Becker JA, Carmasin J, Wadsworth LP, Lorius N, Sullivan C, Maye JE, Gidicsin C, Pepin LC, Sperling RA, Johnson KA, Rentz DM (2012) Subjective cognitive complaints and amyloid burden in cognitively normal older individuals. Neuropsychologia $\mathbf{5 0}$, 2880-2886.

[19] Jessen F, Amariglio RE, Van Boxtel M, Breteler M, Ceccaldi M, Chételat G, Dubois B, Dufouil C, Ellis KA, Van Der Flier WM, Glodzik L, Van Harten AC, De Leon MJ, McHugh P, Mielke MM, Molinuevo JL, Mosconi L, Osorio RS, Perrotin A, Petersen RC, Rabin LA, Rami L, Reisberg B, Rentz DM, Sachdev PS, De La Sayette V, Saykin AJ, Scheltens P, Shulman MB, Slavin MJ, Sperling RA, Stewart R, Uspenskaya O, Vellas B, Visser PJ, Wagner M (2014) A conceptual framework for research on subjective cognitive decline in preclinical Alzheimer's disease. Alzheimers Dement 10, 844-852.

[20] McKhann GM, Knopman DS, Chertkow H, Hyman BT, Jack CR, Kawas CH, Klunk WE, Koroshetz WJ, Manly JJ, Mayeux R, Mohs RC, Morris JC, Rossor MN, Scheltens P, Carrillo MC, Thies B, Weintraub S, Phelps $\mathrm{CH}$ (2011) The diagnosis of dementia due to Alzheimer's disease: Recommendations from the National Institute on Aging-Alzheimer's Association workgroups on diagnostic guidelines for Alzheimer's disease. Alzheimers Dement 7, 263-269.

[21] Albert MS, DeKosky ST, Dickson D, Dubois B, Feldman HH, Fox NC, Gamst A, Holtzman DM, Jagust WJ, Petersen RC, Snyder PJ, Carrillo MC, Thies B, Phelps CH (2011) The diagnosis of mild cognitive impairment due to Alzheimer's disease: Recommendations from the National Institute on Aging-Alzheimer's Association workgroups on diagnostic guidelines for Alzheimer's disease. Alzheimers Dement 7, 270-279.

[22] Molinuevo JL, Rabin LA, Amariglio R, Buckley R, Dubois B, Ellis KA, Ewers M, Hampel H, Kloppel S, Rami L, Reisberg B, Saykin AJ, Sikkes S, Smart CM, Snitz BE, Sperling R, van der Flier WM, Wagner M, Jessen F (2017) Implementation of subjective cognitive decline criteria in research studies. Alzheimers Dement 13, 296-311.

[23] Burton EJ, Barber R, Mukaetova-Ladinska EB, Robson J, Perry RH, Jaros E, Kalaria RN, O'Brien JT (2009) Medial temporal lobe atrophy on MRI differentiates Alzheimer's disease from dementia with Lewy bodies and vascular cognitive impairment: A prospective study with pathological verification of diagnosis. Brain 132, 195-203.

[24] Roman GC, Tatemichi TK, Erkinjuntti T, Cummings JL, Masdeu JC, Garcia JH, Amaducci L, Orgogozo JM, Brun A, Hofman A (1993) Vascular dementia: Diagnostic criteria for research studies. Report of the NINDS-AIREN International Workshop. Neurology 43, 250-260.
[25] Folstein MF, Folstein SE, McHugh PR (1975) "Minimental state": A practical method for grading the cognitive state of patients for the clinician. J Psychiatr Res 12, 189-198.

[26] Lawton MP, Brody EM (1969) Assessment of older people: Self-maintaining and instrumental activities of daily living. Gerontologist 9, 179-186.

[27] Carlesimo G, Buccione I, Fadda L, Graceffa A, Mauri M, Lorusso S, Bevilacqua G, Caltagirone C (2002) Normative data of two memory tasks: Short-Story recall and Rey's Figure. Nuova Riv Neurol 12, 1-13.

[28] Orsini A, Grossi D, Capitani E, Laiacona M, Papagno C, Vallar G (1987) Verbal and spatial immediate memory span: Normative data from 1355 adults and 1112 children. Ital $J$ Neurol Sci 8, 539-548.

[29] Spinnler H, Tognoni G (1987) Standardizzazione e Taratura Italiana di Test Neuropsicologici. Masson Italia Periodici, Milano.

[30] Giovagnoli AR, Del Pesce M, Mascheroni S, Simoncelli M, Laiacona M, Capitani E (1996) Trail Making Test: Normative values from 287 normal adult controls. Ital J Neurol Sci 17, 305-309.

[31] van Gorp W, Satz P, Kiersch ME, Henry R (1986) Normative data on the Boston Naming Test for group of normal older adults. J Clin Exp Neuropsychol 8, 702-705.

[32] Novelli G, Papagno C, Capitani E, Laiacona M, Vallar G, Cappa S (1986) Tre test clinici di ricerca e produzione lessicale. Taratura su soggetti normali. Arch Psicol Neurol Psichiatr 47, 477-506.

[33] Shulman KI, Pushkar Gold D, Cohen CA, Zucchero CA (1993) Clock-drawing and dementia in the community: A longitudinal study. Int J Geriatr Psychiatry 8, 487-496.

[34] Appollonio I, Leone M, Isella V, Piamarta F, Consoli T, Villa ML, Forapani E, Russo A, Nichelli P (2005) The Frontal Assessment Battery (FAB): Normative values in an Italian population sample. Neurol Sci 26, 108-116.

[35] Basso A, Capitani E, Laiacona M (1987) Raven's Coloured Progressive Matrices: Normative values on 305 adult normal controls. Funct Neurol 2, 189-194.

[36] Raven JC, (Firm) HKL (1958) Standard progressive matrices: Sets $A, B, C, D$ and $E$. H.K. Lewis, London.

[37] Conte A, Leodori G, Ferrazzano G, De Bartolo MI, Manzo N, Fabbrini G, Berardelli A (2016) Somatosensory temporal discrimination threshold in Parkinson's disease parallels disease severity and duration. Clin Neurophysiol 127, 29852989.

[38] Lee MS, Lee MJ, Conte A, Berardelli A (2018) Abnormal somatosensory temporal discrimination in Parkinson's disease: Pathophysiological correlates and role in motor control deficits. Clin Neurophysiol 129, 442-447.

[39] Conte A, Modugno N, Lena F, Dispenza S, Gandolfi B, Iezzi E, Fabbrini G, Berardelli A (2010) Subthalamic nucleus stimulation and somatosensory temporal discrimination in Parkinson's disease. Brain 133, 2656-2663.

[40] Conte A, Rocchi L, Ferrazzano G, Leodori G, Bologna M, Li Voti P, Nardella A, Berardelli A (2014) Primary somatosensory cortical plasticity and tactile temporal discrimination in focal hand dystonia. Clin Neurophysiol 125, 537-543.

[41] Conte A, Belvisi D, Tartaglia M, Cortese FN, Baione V, Battista E, Zhu XY, Fabbrini G, Berardelli A (2017) Abnormal temporal coupling of tactile perception and motor action in Parkinson's disease. Front Neurol 8, 249.

[42] Ramos VFML, Esquenazi A, Villegas MAF, Wu T, Hallett M (2016) Temporal discrimination threshold with healthy aging. Neurobiol Aging 43, 174-179. 
[43] Pastor MA, Macaluso E, Day BL, Frackowiak RSJ (2008) Putaminal activity is related to perceptual certainty. $\mathrm{Neu}$ roimage 41, 123-129.

[44] Braak H, Braak E (1991) Neuropathological stageing of Alzheimer-related changes. Acta Neuropathol 82, 239-259.

[45] Harrington DL, Boyd LA, Mayer AR, Sheltraw DM, Lee RR, Huang M, Rao SM (2004) Neural representation of interval encoding and decision making. Cogn Brain Res 21, 193-205.

[46] Nieoullon A (2002) Dopamine and the regulation of cognition and attention. Prog Neurobiol 67, 53-83.

[47] Reeves SJ, Grasby PM, Howard RJ, Bantick RA, Asselin MC, Mehta MA (2005) A positron emission tomography (PET) investigation of the role of striatal dopamine (D2) receptor availability in spatial cognition. Neuroimage $\mathbf{2 8}$, 216-226.

[48] Van Schouwenburg MR, Den Ouden HEM, Cools R (2015) Selective attentional enhancement and inhibition of frontoposterior connectivity by the basal ganglia during attention switching. Cereb Cortex 25, 1527-1534.

[49] Tommasi G, Fiorio M, Yelnik J, Krack P, Sala F, Schmitt E, Fraix V, Bertolasi L, Le Bas J-F, Ricciardi GK, Fiaschi A, Theeuwes J, Pollak P, Chelazzi L (2015) Disentangling the role of cortico-basal ganglia loops in top-down and bottomup visual attention: An investigation of attention deficits in Parkinson disease. J Cogn Neurosci 27, 1215-1237.

[50] Arsalidou M, Duerden EG, Taylor MJ (2013) The centre of the brain: Topographical model of motor, cognitive, affective, and somatosensory functions of the basal ganglia. Hum Brain Mapp 34, 3031-3054.

[51] Marinho V, Oliveira T, Rocha K, Ribeiro J, Bento T, Pinto GR, Velasques B, Giorgio L Di, Orsini M, Gupta DS, Bittencourt J, Bastos VH, Teixeira S, Marinho V, Oliveira T, Rocha K, Ribeiro J, Bento T, Pinto GR, Velasques B, Ribeiro P, Giorgio L Di, Orsini M, Gupta DS, Bittencourt J, Bastos VH, Teixeira S (2018) The dopaminergic system dynamic in the time perception: A review of the evidence. Int J Neurosci 128, 262-282.

[52] Lewis PA, Miall RC (2006) Remembering the time: A continuous clock. Trends Cogn Sci 10, 401-406.
[53] Buhusi CV (2003) Dopaminergic mechanisms of interval timing and attention. In Functional and neural mechanisms of interval timing, Meck WH, ed. CRC Press, Boca Raton, FL, pp. 317-338.

[54] McNab F, Klingberg T (2008) Prefrontal cortex and basal ganglia control access to working memory. Nat Neurosci 11, 103-107.

[55] Egerton A, Mehta MA, Montgomery AJ, Lappin JM, Howes OD, Reeves SJ, Cunningham VJ, Grasby PM (2013) The dopaminergic basis of human behaviors: A review of molecular imaging studies. Neurosci Biobehav Rev 33, 1109-1132.

[56] Nobili A, Latagliata EC, Viscomi MT, Cavallucci V, Cutuli D, Giacovazzo G, Krashia P, Rizzo FR, Marino R, Federici M, De Bartolo P, Aversa D, Dell'Acqua MC, Cordella A, Sancandi M, Keller F, Petrosini L, Puglisi-Allegra S, Mercuri NB, Coccurello R, Berretta N, D'Amelio M (2017) Dopamine neuronal loss contributes to memory and reward dysfunction in a model of Alzheimer's disease. Nat Commun 8, 14727.

[57] De Marco M, Venneri A (2018) Volume and connectivity of the ventral tegmental area are linked to neurocognitive signatures of Alzheimer's disease in humans. J Alzheimers Dis 63, 167-180.

[58] Gibbon J (1977) Scalar Expectancy Theory and Weber's Law in Animal Timing. Psychol Rev 84, 279-325

[59] Church RM (1984) Properties of the internal clock. Ann N $Y$ Acad Sci 423, 566-582.

[60] Coull JT, Vidal F, Nazarian B, Macar F (2004) Functional anatomy of the attentional modulation of time estimation. Science 303, 1506-1509.

[61] Coull JT, Cheng R, Meck WH (2010) Neuroanatomical and neurochemical substrates of timing. Neuropsychopharmacology 36, 3-25.

[62] Tamura Y, Matsuhashi M, Lin P, Ou B, Vorbach S, Kakigi $R$, Hallett M (2008) Impaired intracortical inhibition in the primary somatosensory cortex in focal hand dystonia. Mov Disord 23, 558-565. 